mation available to us; and many staff of the Medical Research Council Environmental Epidemiology Unit for their help, particularly Mick Merwood for computer analyses and Gill Strange for preparing the manuscript. Professor Geoffrey Rose kindly commented on an earlier version of the paper. The study was approved by the British Medica Association ethical committee and the West Cumbria ethics of research committee and was supported partially by a grant from the Department of Health.

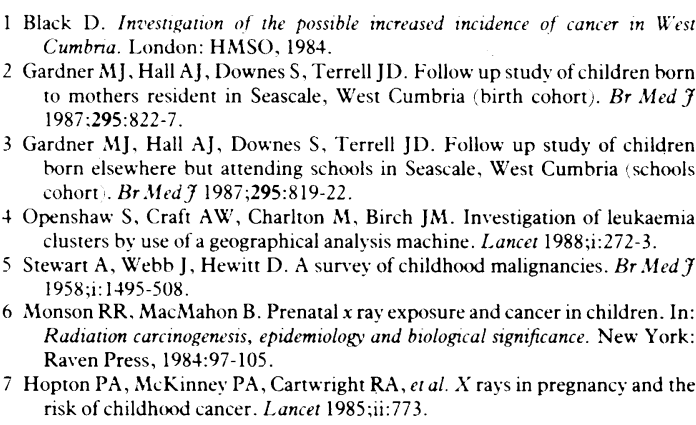
Cumbra. London: HMSO, 1984.

2 Gardner MJ. Hall AJ, Downes S, Terrell JD. Follow up study of children born to mothers resident in Seascale, West Cumbria (birth cohort). Br Med 1987:295:822-7.

Gardner MJ, Hall AJ, Downes S, Terrell JD. Follow up study of children horn elsewhere but attending schools in Seascale, West Cumbria schools cohort Br.Med f 1987;295:819-22.

+ Openshaw S, Craft AW, Charlton M. Birch JM. Investigation of leukaemia clusters by use of a geographical analysis machine. Lancet 1988;i:272-3.

5 Stewart A, Webb J, Hewitt D. A survey of childhood malignancies. Br.Med $\mathcal{J}$ 1958;i:1495-508.

Monson RR MacMahon B. Prenatal $x$ ray exposure and cancer in children. Radiation carcinogenesis, epidemiology and biological significance. New York: Raven Press, 1984:97-105.

Hopton PA, McKinney PA, Cartwright RA, et al. $X$ rays in pregnancy and the risk of childhood cancer. Lancet 1985;ii:773.

8 Knox EG, Stewart AM, Kneale GW, Gilman EA. Prenatal irradiation and childhood cancer. F Soc Radiol Prot 1987;7:3-15.

9 Doll R. The epidemiology of childhood leukaemia. $f R$ Statist Soc $(A$ 1989;152:341-51

10 Adelstein AM, Donovan JW. Malignant disease in children whose mother had chicken pox, mumps or rubella in pregnancy. Br Med f 1972;iv:629-31. 11 Fedrick J, Alberman ED. Reported influenza in pregnancy and subsequent cancer in the child. Br Med F 1972;ii:485-8.

12 Draper GJ, Birch JM, Bithell JF, et al. Childhood cancer in Britain: incidence, survizal and mortality. London: HMSO, 1982. OOffice of Population

13 Gardner MJ, Winter PD. Cancer in Cumberland during $1959-78$ with reference to cancer in young people around Windscale. Lancet 1984;i:216-7.

14 Urquhart J, Palmer M. Cutler J. Cancer in Cumbria: the Windscale connection. Lancet 1984; i:217-8.

15 Craft AW, Openshaw S, Birch J. Apparent cluster of childhord malignancies in Northern England. Lancet 1984;ii: $96-7$.

16 General Register Office. Classification of Occupations, 1966. London: HMSO, 1966

17 Central Statistical Office. Standard Industrial Classification. Revised 1968 London: HMSO, 1968

18 National Radiological Protection Board. Radiation dose histories at British Nuclear Fuels plc, Sellafield. Chilton: NRPB, 1986. (NRPB-M136.

19 Smith PG, Douglas AJ. Mortality of workers at the Sellafield plant of British Nuclear Fuels. Br.Med f 1986;293:845-54.

20 Gardner MJ, Snee MP, Hall AJ, Powell CA, Downes S, Terell JD. Results of case-control study of leukaemia and lymphoma among young people near Sellafield nuclear plant in West Cumbria. Br Med F 1990;300:423-9.

Accepted 29 fanuar 1990
Departments of Child Health and Community Health, Leicester Royal Infirmary, PO Box 65, Leicester LE2 7LX A C Fenton, MRCP, research registrar in child health D J Field, DM, senior lecturer in child health

E Mason, MPHIL, research associate in community health $M$ Clarke, FFCM, professor in community health

Correspondence to: Dr Field

Br.Med f 1990;300:43+-6

\title{
Attitudes to viability of preterm infants and their effect on figures for perinatal mortality
}

\author{
A C Fenton, D J Field, E Mason, M Clarke
}

\section{Abstract}

Objective-To examine how local attitudes to management of extreme preterm labour can influence data on perinatal mortality.

Design-One year prospective study in a geographically defined population.

Setting - The 17 perinatal units of Trent region.

Patients-All preterm infants of $\leqslant 32$ weeks' gestation in the Trent region.

Interventions - Infants who had been considered viable at birth were referred for intensive care; those who had been considered non-viable received terminal care.

Main outcome measures-Whether each infant was born alive, dead, or alive but considered nonviable.

Results-Large differences were observed among units in the rates of delivery of infants of $\leqslant 27$ weeks' gestation (rates varied from $7 \cdot 2$ to 0 per 1000 births). These differences were not present in the data relating to infants of between 28 and 32 weeks' gestation. The variation seemed to result from different approaches to the management of extreme preterm labour-that is, whether management took place in a labour ward or a gynaecology ward.

Conclusions-Place of delivery of premature babies ( $\leqslant 27$ weeks' gestation) may influence classification and hence figures for perinatal mortality. In addition, the fact that the onus of judgment regarding viability and classification is often placed on relatively junior staff might also affect the figures for perinatal mortality. The introduction of a standard recording system for all infants $>500 \mathrm{~g}$ would be advantageous.

\section{Introduction}

Perinatal mortality still commands ënsiderable attention from the media, politicians, and the public in general.' In contrast, the medical profession has become increasingly unwilling to rely on its measurement for assessing perinatal care. Problems that have been identified include a lack of uniformity in assessing both viability and signs of life $^{2}$ and the influence of neonatal intensive care causing infants to be sustained beyond the perinatal period. ${ }^{3}$ We examined the extent to which variation in the management of preterm labour might influence perinatal mortality.

\section{Methods}

We undertook a one year prospective study (1 February 1987 to 31 January 1988) in the 17 perinatal units of the Trent region. Our intention was to identify all births at $\leqslant 32$ weeks' gestation. Data were collected by independent observers. Information was available from two sources.

(1) Labour ward records allowed the identification of all infants in the study group who were not referred for any neonatal care. These babies remained in the labour ward either because they were considered dead at delivery or because local policy was to give terminal care in the labour ward to infants considered nonviable. The records detailed birth weight, gestation, and whether the baby was born alive or dead. They did not indicate the criteria chosen to make these decisions or the grade of staff present at the delivery.

(2) Examination of the case notes of all babies admitted to individual neonatal units identified those infants given active care and those given terminal care.

\section{Results}

From the data it was possible to identify three groups of infants: $(a)$ those referred for active neonatal intervention; $(b)$ those considered to have shown no signs of life; and (c) those who died soon after birth either in the labour ward or after transfer to the neonatal unit for terminal care.

Table I gives the numbers of babies from each hospital who were referred for intensive care and of those considered to be dead at birth or who died without active neonatal intervention. Infants were further subdivided into those of $\leqslant 27$ weeks' gestation 
and those between 28 and 32 weeks' gestation. Table II gives the rates per 1000 total births for each unit of infants who were born dead or considered non-viable and those who were admitted for active care.

The results in table II show two different patterns. For those infants of $\geqslant 28$ weeks' gestation (that is, a gestation at which under present legislation all births are considered viable) there was a small, relatively constant rate of stillbirths that may represent part of the "natural wastage" of pregnancy. No baby of this gestation was considered to have been born alive and not given intensive care. The fluctuations in the rates of admission of infants was probably due both to differences in local populations and to the concentration of cases in the neonatal referral centres (hospitals 4,6 , 10,12 , and 16).

For deliveries at $\leqslant 27$ weeks' gestation the rates of admission for active care fluctuated widely among units, there being a less noticeable percentage difference between the rate in the referral centres and some of the other units than for infants of 28-32 weeks' gestation. There was also a dissimilar pattern in terms of infants who showed no signs of life at birth (these infants cannot be classified as stillbirths as under present legislation this term refers specifically to infants born after 28 weeks' gestation), with considerable differences among units as opposed to the relatively constant rates in infants of 28-32 weeks' gestation.

\section{Discussion}

A potential problem of interpreting these data is that the figures are based on individual units rather than on health districts. We thought it important, however, to analyse the data in this way to explore variations in perinatal mortality resulting from differences in management rather than from differences in the local population.

There are three possible explanations for the observed variations in patterns of care between infants of 28-32 weeks' gestation and those of $\leqslant 27$ weeks' gestation. Firstly, some units might have selectively transferred mothers in preterm labour before 28 weeks of pregnancy. This seems unlikely as during the study period in the entire region there were only 10 transfers in utero of babies of $\leqslant 27$ weeks' gestation. Secondly, there may have been differences in the population in terms of risk factors for preterm labour and fetal peripartum death. This again would seem unlikely, given the relatively constant rate of stillbirths across al the units for infants of 28-32 weeks' gestation. Thirdly, differences in management strategies could be responsible for the fluctuations. The data indicate that some hospitals chose to deliver all infants of $\geqslant 20$ weeks' gestation in the labour ward. These infants can then be

TABLE I - Number of infants of $\leqslant 27$ weeks' and 28-32 weeks' gestation referred for intensive care and number considered to be dead or non-viable at birth in 17 perinatal units in Trent region

\begin{tabular}{|c|c|c|c|c|c|}
\hline \multirow[b]{2}{*}{ Hospital No } & \multirow[b]{2}{*}{ Total No of deliveries } & \multicolumn{2}{|c|}{$\begin{array}{l}\text { No of admissions for } \\
\text { active care }\end{array}$} & \multicolumn{2}{|c|}{$\begin{array}{l}\text { No of stillbirths plus } \\
\text { non-viable infants }\end{array}$} \\
\hline & & $\leqslant 27$ Weeks & 28-32 Weeks & $\leqslant 27$ Weeks & 28-32 Weeks \\
\hline 1 & 2669 & 4 & 21 & 0 & 1 \\
\hline 2 & 3175 & 13 & 33 & 2 & 6 \\
\hline 3 & 4696 & 12 & 41 & 1 & 2 \\
\hline 4 & 3011 & 23 & 63 & l & 5 \\
\hline 5 & 2107 & 0 & 10 & 0 & 0 \\
\hline 6 & 5887 & 15 & 110 & 28 & 7 \\
\hline 7 & 2401 & 3 & 28 & 0 & 3 \\
\hline 8 & 1061 & 4 & 9 & 3 & 1 \\
\hline 9 & 3456 & 4 & 21 & 1 & 5 \\
\hline 10 & 4690 & 10 & 62 & 0 & 8 \\
\hline 11 & 2497 & 3 & 30 & 18 & 8 \\
\hline 12 & 5011 & 8 & 74 & 3 & 7 \\
\hline 13 & 2738 & 10 & 34 & 4 & 3 \\
\hline 14 & 1028 & 1 & 8 & 0 & 1 \\
\hline 15 & 1831 & 5 & 13 & 2 & 5 \\
\hline 16 & 6136 & 18 & 91 & 14 & 13 \\
\hline 17 & 3296 & 3 & 35 & 2 & 3 \\
\hline
\end{tabular}

TABLE II $-N$ umber (rate/1000 births) of infants of $\leqslant 27$ weeks' and 28-32 weeks' gestation considered to be dead or non-viable at birth and number (rate/1000 births) referred for intensive care in 17 perinatal units in Trent region

\begin{tabular}{|c|c|c|c|c|}
\hline \multirow[b]{2}{*}{ Hospital No } & \multicolumn{2}{|c|}{$\begin{array}{l}\text { No considered dead or } \\
\text { non-viable at birth }\end{array}$} & \multicolumn{2}{|c|}{ No admitted for active care } \\
\hline & $\leqslant 27$ Weeks & 28-32 Weeks & $\leqslant 27$ Weeks & 28-32 Weeks \\
\hline 1 & 0.000 & $0 \cdot 370$ & 1.500 & $7 \cdot 870$ \\
\hline 2 & 0.630 & 1.890 & 1.570 & $10 \cdot 390$ \\
\hline 3 & 0.000 & 0.210 & $2 \cdot 560$ & 8.730 \\
\hline $4^{\star}$ & 0.330 & 1.660 & $7 \cdot 640$ & 20.920 \\
\hline 5 & 0.000 & 0.000 & 0.000 & 4.750 \\
\hline $6^{\star}$ & $4 \cdot 760$ & $1 \cdot 190$ & $2 \cdot 550$ & 18.690 \\
\hline 7 & 0.000 & $1 \cdot 250$ & $1 \cdot 250$ & 11.660 \\
\hline 8 & 2.830 & 0.940 & $3 \cdot 770$ & $8 \cdot 480$ \\
\hline 9 & $0 \cdot 290$ & 1.450 & $1 \cdot 160$ & 6.080 \\
\hline $10^{\star}$ & $0 \cdot 000$ & 1.710 & $2 \cdot 130$ & $13 \cdot 220$ \\
\hline 11 & $7 \cdot 210$ & $3 \cdot 200$ & $1 \cdot 200$ & 12.010 \\
\hline $12^{\star}$ & 0.600 & 1.400 & 1.600 & 14.770 \\
\hline 13 & 1.460 & $1 \cdot 100$ & 3.650 & 12.420 \\
\hline 14 & 0.000 & 0.970 & 0.970 & $7 \cdot 780$ \\
\hline 15 & 1.090 & $2 \cdot 730$ & $2 \cdot 730$ & $7 \cdot 100$ \\
\hline $16^{\star}$ & $2 \cdot 120$ & $2 \cdot 120$ & 2.930 & 14.830 \\
\hline 17 & 0.610 & 0.910 & 0.910 & $10 \cdot 620$ \\
\hline
\end{tabular}

* Neonatal referral centre.

considered as live births and thus can be included in perinatal mortality statistics. Where unit policy is to deliver extreme preterm infants away from the maternity unit the question of viability (and hence inclusion in perinatal mortality) does not arise.

For infants of $\leqslant 27$ weeks' gestation who are delivered in the labour ward difficult decisions regarding whether they are live births or abortions have to be made. By definition, infants with a heart rate should be considered as live births and therefore potential neonatal deaths. Attendant medical and midwifery staff, however, may be confident that the infant is not viable and believe that by classifying the baby as being alive they subject the parents to additional, distressing registration procedures and often funeral expenses. The situation is complicated still further if the baby is the product of a late therapeutic abortion.

The combined effect of place of delivery and difficulty in classifying extremely preterm infants can explain some of the large anomalies in the data. For example, two of the hospitals (6 and 12) both served populations comparable in size (5887 deliveries and 5011 deliveries respectively), characteristics, and provision of perinatal services, yet they had an almost eightfold difference in the rate of infants of $\leqslant 27$ weeks' gestation showing no signs of life or being nonviable. This contrasts with about a twofold difference in rates of admission for infants of $\leqslant 27$ weeks' gestation for active care (hospital 6, 15 admissions; hospital 12,8 admissions). If perinatal mortality was calculated for individual hospitals such differences would clearly have an important influence.

We believe that these anomalies could be removed by introducing a statutory requirement to register all infants weighing $\geqslant 500 \mathrm{~g}$, regardless of place of delivery, as suggested by the World Health Organisation. ${ }^{+}$In addition, decisions regarding funeral arrangements for registered babies should be in accordance with the wishes of the parents, allowing those who wish to do so to hold a funeral. The disposal of the remainder of these babies would be the responsibility of each hospital. Such humane practice is not uniformly available at present.

We do not have any data to confirm that introducing a system based on infants' weight would produce more accurate reporting but believe it has several advantages over the present system, in which the onus of deciding whether an infant is born alive, a stillbirth, or the result of an abortion rests with the attendant staff at delivery. Any new system should require staff to record only variables such as weight, heart rate, respiratory effort, and estimated gestation. This system would avoid the 
complex issue of viability, which is determined by a combination of clinical features of which condition at birth is only one.

We thank all of the medical, nursing, and clerical staff of the 17 perinatal units in the Trent region for their help. This work was funded by Trent Regional Health Authority. ACF is funded by the Spastics Society.
1 Brindle D. MPs call for action to cut baby deaths: targets urged for health regions to improve services. Guardian 1988 Dec 14:2 ( $\mathrm{col} 5$ ).

2 Keirse MJMC. Perinatal mortality rates do not contain what they purport to contain. Lancet 1984; i:1166-9.

3 Field DJ, Smith H, Mason E, Milner AD. Is perinatal mortality still a good indicator of perinatal care? Paediatric and Perinatal Epidemiology 1988;2:2139.

4 World Health Organisation. International classification of diseases, injuries and causes of death. 9th Revision, 1975. Geneva: WHO, 1977:765-6.

(Accepted 11 December 1989)

\title{
Prolonged endometrial stimulation associated with oestradiol implants
}

\author{
Kevin F Gangar, David Fraser, Malcolm I Whitehead, Michael P Cust
}

\begin{abstract}
Objective-To provide information on endometrial stimulation after discontinuation of treatment with oestradiol implants.

Design-Long term follow up of withdrawal bleeding patterns in women taking progestogens cyclically every month after oestradiol implant treatment was ended.

Setting-Specialist menopause clinic.

Subjects - 10 Postmenopausal patients (at least 12 months' amenorrhoea after the last spontaneous period) who were treated with oestradiol implants for typical symptoms of oestrogen deficiency. The oestradiol dose was $50 \mathrm{mg}$, reimplantation occurring roughly every six months. Patients subsequently either needed to discontinue the hormone treatment for medical reasons or expressed a desire to stop treatment.
\end{abstract}

Main outcome measure-Duration of endometrial stimulation-defined as the presence of withdrawal bleeding in response to progestogen given cyclically - after insertion of the last oestradiol implant.

Results-Four patients eventually stopped bleeding, their mean duration of bleeding being 35 months (range 27-43 months). One patient required hysterectomy 26 months after the last implantation because of persistent irregular bleeding despite treatment with high doses of progestogen. Three patients bled for 22,30 , and 36 months and then restarted oestrogen treatment because symptoms returned. The last two patients subsequently continued to bleed 12 and 21 months after the last implantation.

Conclusions - The duration of endometrial stimulation after implantation can be prolonged, up to 43 months. Insertion of oestradiol implants can carry a long term commitment to the cyclical administration of progestogen and regular withdrawal bleeding if endometrial hyperplasia and carcinoma are to be avoided.

College School of Medicine and Dentistry, London SE5 8RX, and Menopause Clinic, Chelsea Hospital for Women, London SW3 Kevin F Gangar, MRCOG, research fellow

David Fraser, $\mathrm{MB}$, research fellow

Malcolm I Whitehead,

FRCOG, senior lecturer and consultant

Michael P Cust, MRCOG, research fellow

Correspondence to: Mr Gangar. prevent endometrial neoplasia. ${ }^{3}$ Progestogenic effects such as physical and psychological symptoms ${ }^{4}$ and the re-establishment of vaginal bleeding are, however, disliked by some women and may reduce compliance.

The information provided in the Data Sheet Compendium and the British National Formulary on the duration of oestradiol implants is inconsistent. The compendium states that the "frequency of replacement [of implants] depends on the duration of activity of the implants administered and the severity of the symptoms. Patients require a further implant when symptoms return, usually every 4 to 8 months." "The British National Formulary states that the duration of 25,50 , and $100 \mathrm{mg}$ oestradiol implants is 36,44 , and 57 weeks, respectively. ${ }^{6}$ The manufacturers in the United Kingdom were unable to provide us with information on how the recommendations in the British National Formulary had been derived (Akzo, personal communication). Furthermore, the meaning of duration is ambiguous. It is not clear whether this term applies only to the relief of symptoms or to stimulation of vulnerable end organs such as the endometrium as well.

To provide information on the stimulatory effects of oestradiol implants on the endometrium we followed up a series of postmenopausal women for between one and three and a half years after they were given their last implant. We considered that endometrial stimulation was occurring if the cyclic addition of a progestogen every month induced a regular withdrawal bleed.

\section{Patients and methods}

All 10 patients had initially presented with at least 12 months' amenorrhoea and had complained of flushes, sweats, and vaginal dryness. One patient (case 7) had undergone bilateral oophorectomy for endometriosis. All received oestradiol $50 \mathrm{mg}$ (Akzo, Oss, The Netherlands), reimplantation occurring roughly every six months, and a progestogen was added for 10-12 days each calendar month. Eventually, further implantation was not performed for the reasons stated in the table, but patients continued to attend the clinic regularly. After the final implantation progestogens were continued for 10-12 days each month, and all patients experienced bleeding after withdrawal of progestogen. No other oestrogens were given during this time, which was verified from the records of the family doctors. We have called the time after the last implantation when cyclic bleeding occurred in relation to progestogen treatment the observation period. At least four venous blood samples were collected from three patients during the observation period for measurement of plasma oestradiol concentrations in either the endocrine unit at the Chelsea Hospital for Women or the department of reproductive medicine at King's College Hospital.

\section{Results}

The mean age before treatment with oestradiol implants was $51 \cdot 2$ years (range 35 to 62 ). The mean age at the end of the observation period was 56.0 (range 42 to 68 ). The table shows the time between the first and 